\title{
Innovative culture thesaurus of the future manager of the educational institution
}

\author{
D. Kozlov \\ A.S. Makarenko Sumy State Pedagogical University, Sumy, Ukraine \\ Corresponding author: E-mail: fpdo@sspu.sumy.ua
}

Paper received 05.11.19; Accepted for publication 19.11.19.

\section{https://doi.org/10.31174/SEND-PP2019-209VII86-07}

\begin{abstract}
The key issues related to innovative culture thesaurus of the future manager of the educational institution and its functions is considered. The state of research the concept of "thesaurus" is analyzed. This paper explores the essential theoretical conceptual properties of innovation, which is considered a system enabling to argue that a system-wide definition of the innovation concept is the most preferable in terms of comprehensiveness. From a theoretical perspective, we have provided insight into the innovative culture of the future manager of the educational institution, and presented a set of innovation functions, including intensive development.
\end{abstract}

Keywords: thesaurus, innovative culture, future manager, educational institution, components, functions.

Introduction. Although the problems of innovations thesaurus as a source of competitive business advantages in a changeable environment need a long time to emerge, there is no consistent definition of innovative culture of the future manager of the educational institution. The ability to be innovative is important for running a successful and long-term sustainable company, moreover the educational institution being a strategic asset that helps solidify or grow a company's competitive advantage [2, p. 4]. An innovation culture can be defined as "a multi-dimensional context which includes the intention to be innovative, the infrastructure to support innovation, operational level behaviors necessary influencing a market and value orientation, and the environment to implement innovation" $[4, \mathrm{p}$. 540].

Consequently, there is a need for a comprehensive research analysis of the innovative culture thesaurus of the future manager of the educational institution and its functions.

Analysis of latest researches and publications. The analysis of the scientific literature proves that today there are no common approaches defining the main characteristic of an innovative culture, which is considered as a level of professionalism, which is manifested in the ability to objectively evaluate new ideas, in the willingness to creatively master and use all new, progressive (Isaev V.) [8], as a system of values that correspond to the innovative development of society, state, regions... organizations, institutions and reflect the individual-psychological qualities, other major societies the person's values that contribute to the formation and development of an innovatively active personality" (Noskov V.) [16, p. 71], as a sphere of spiritual life, reflecting its value orientation, which is enshrined in motives, knowledge, skills, role models and standards of behavior, and provides with the perception of new ideas, willingness and ability to support and implement innovations in all life spheres (Kholodkova L.) [9, p.10], as a general culture component (Kozlova O. G., Milenkova R.V.) [10, p. 22].

Meanwhile an innovative culture can be defined as a culture that utilizes the full "all the employees' creative potential and their knowledge about customers, competitors, and processes" [13, p. 38)]. Another definition by Kraśnicka, Głód, \& Wronka-Pośpiech calls an innovative culture, a culture that "stimulates the generation of new solutions or their absorption from the outside and contributes to the more effective implementation of creative ideas" $[11$, p. 745]. There have been a lot of papers on the topic in the recent years, but most of them are either confined to a single specific case or are neither peer reviewed nor use scientific methods. Thus, the issues of innovative culture thesaurus of the future manager of the educational institution and its functions are becoming relevant nowadays.

The aim of the article. To conduct a comprehensive research analysis of innovative culture thesaurus of the future manager of the educational institution and its functions.

Research Methods: Solving the highlighted aim, a set of methods of scientific research adequate to them were used, theoretical: a comparative analysis of the scientific definitions of the innovative culture as an integrative personality quality of the future manager of the educational institution, a systematic analysis of its functions.

Results. Nowadays in computer science and theory of artificial intelligence drawn attention to the systematization of the thesaurus data and its orientational character. Thesaurus as a way of systematic representation of knowledge and the variety of ideographic vocabulary is considered by N.I. Gendin as an ambiguous word having, as at least two values:

1. Thesaurus information is called a stock knowledge (concepts, judgments) placed in the memory of the subject perceiving the information as structured knowledge in the form of concepts and the semantic relations between them.

2 . Thesaurus is a dictionary of the special type or ideographic dictionary in which words are arranged according to the degree of semantic closeness [7, p. 5].

The basic concept of a scientific thesaurus of innovative culture is the concept of "innovation". Innovation (in -, novus - new) in Latin means an update, change, introduction of something new, a process of putting a scientific idea into practice. In methodological terms, innovation is the idea (s), proposals, scientific developments that can and become the basis creation form of new development strategies, new products types, significantly improve consumer characteristics (economic, cultural, educational, technical, etc.) of existing phenomena and processes, goods, the creation of new objects of material and perfect 
being. According to V.G. Kremen, anything that can improve the life quality and the process of human development is an innovation [12, p. 223].

Peter Ferdinand Drucker, American economist, argued that the introduction of innovations is a science subject to development [6]. Drucker distinguishes the following sources of innovative ideas: 1. An unexpected event (unexpected success, failure, an external event); 2 . incongruence (a discrepancy between the reality and its perception); 3. the inventions for the process needs (imperfection and failures to be eliminated); 4. instant changes in the composition of economic activity type or market; 5 . demographic changes; 6 . changes in understanding, location and important adjustments; 7. new knowledge (scientific, unscientific) [6]. So, the distinguishing features of innovations are novelty, innovativeness, industrial applicability, marketing, obtaining economic and/or other effects.

So, for this article, an innovative culture is defined as a culture that facilitates the generation and implementation of innovations utilizing the full employees' potential. After analyzing the existing relevant literature on the topic, two general approaches to the thesaurus of an innovative culture emerged. The first way, that tried to break down the pretty impalpable subject of an innovative culture into smaller, more palatable parts [1]. The second one being an effort of trying to measure the innovativeness of a culture using numerical indicators. Frameworks that try to do that have been proposed by [1]; [2]; [4]. This would allow for an analytical approach to the thematic, and can help the future manager of educational institution to benchmark progress towards a more innovative culture [4. p. 554].

It should be noted that culture as a phenomenon cannot exist outside its medium (individual, group of persons or organization), just as every individual has a certain culture level, a certain set of values and social attitudes.

Innovative culture is person's orientation, education, training for development in accordance with the society requirements, enhancing his social abilities in the pedagogical process, restructuring the educational content in accordance with the life requirements, the activities interconnection within educational process. Different interpretations of the innovative culture of the future manager of the educational institution can be defined. In particular, first of all, the future manager's awareness in the sphere of modern education, sufficient disciplines knowledge and ability to apply new, advanced experience, constant professional skills improvement, perceiving innovations in the educational process; secondly, the future manager's communication with the participants of the educational process, that is, tasks completion is not in a commanding tone, and conditions creation for the free tasks fulfillment testifies to the culture, the wealth of the future manager's inner world; third, the education and professionalism, the ability to be demanding instills in all the participants of the educational process respect and honor of the future manager of the educational institution; fourth, the ability to interest in the subjects, the rational use of innovative technologies, active learning methods within the educational process are indicators of the innovative culture of the future manager of the educational institution. Through an innovative culture, it is possible to achieve a significant impact on the entire culture of professional activity in educational institutions, with reliance on the cultural traditions of the education and country in general.

In order to show how innovative culture stimulates the creative intellectual activity of the future manager of the educational institution, some of its components need to be considered in more detail: open access to information within the educational institution promotes an atmosphere of mutual trust between managers and participants of the educational process, employees' confidence in their future. It is important to provide information so that all participants of the educational process understand that innovations will benefit them by improving the financial and economic performance of the educational institution. The involvement of creative intellectual co-workers in management decisions that directly influence or relate to their work activities, creates a sense of ownership and importance for the educational institution, contributes to the need for self-expression and self-fulfillment. Approval of staff creative intellectual activity is the main intangible incentive of the future manager to activate their intellectual potential and further develop their abilities. The recognition, appreciation from management, and the inner satisfaction that their ideas and developments are brought to life are enough incentives for most creative personalities of the educational institution.

Shani and Divyapriya define six essential dimensions of innovative culture of the future manager. "Relationships" dimension means that innovations are usually a collective outcome and appear within environment, which encompasses different people with different thinking, different environment and so on. Such environment facilitates innovations growth. "Risk taking" dimension refers to the issue of building such innovative culture that encourage people to try new ideas and not punish them for failures rather than perceive failure as an opportunity to learn. "Resources" refer not only to finances but can be understood in wide sense. Resources also can be time, autonomy and power to produce innovations. It is important when "Knowledge" and information within the educational institution is smoothly shared and it is accessible to the manager. "Rewards" are needed to encourage and motivate people to innovate. Finally, tools are methods and techniques that are used for "Creative thinking, idea management and implementation" [17, p. 3].

The implementation of the innovation principle implies that the managers have a focus on the need for continuous updating of the educational process due to the use of educational innovations and is provided with organizational-managerial, financial-economic and psychological-pedagogical changes. Management of the innovation process (innovation management) involves the implementation of the management cycle: analysis planning - organization - control - regulation - analysis. Innovative approaches form new models of management activity: 1) systematic approach; 2) situational approach; 3) program management; 4) target management; 5) program-purpose management; 6) final results management; 7) cybernetic management; 8) dialogical, collegial, participatory management; 9) management of the educational institution development; 10) management of educational quality; 11) adaptive management; 12) facilitation management; 13) reflective management; 14) personally oriented management; 15) optimization 
management; 16) democratic management; management of innovative processes.

The innovative culture of the future manager does not only ensure the constant creation and implementation of the new, but it includes mechanisms that allow the individual to adapt to changes in various life spheres in particular in the educational institution.

The following functions of the innovative culture of the future manager of the educational institution can be distinguished:

- Creative: involves the creation of new knowledge, technologies, ways of management, knowledge transfer, experience transfer. Researchers pay particular attention to the social task of forming an innovative culture of the future manager of the educational institution, equating it to creative activity culture. In their opinion, the developed innovative culture is the basis of the modern innovative economy [10].

- Adaptation: helps to effectively resolve the contradictions between science, technology, management and education, which ensures high creation efficiency and innovations implementation.

- Axiological: provides continuous knowledge updating in combination with the formation of humanistic values. According to N.D. Vasylenko, innovation culture is a set of values created in the innovation process and represented by innovative products, technologies that have legal, economic or social value [19, p. 171].
- Humanistic: creates the conditions for the most effective individuals' self-realization in the conditions of transformation of social institutions [10].

- Motivational: creates incentives system for implementing new in competitive conditions [15]. The researches believe that an innovative culture helps to create an atmosphere in society in which the new idea is perceived as a value accepted and supported by the society.

- Stratifying: forms new ways of stratifying and differentiating social actors (individuals, organizations, institutions, regions), for example, by the development level and foundation of new technologies.

Conclusions. In conclusion, a comprehensive research of innovative culture thesaurus of the future manager of the educational institution and its functions, describing it as a system, which includes all aspects of innovative process, where an idea is first turned into reality, constantly interacting with an internal or external environment of the business entity, the specifics of the innovative process itself, thus contributing to successful product/service launch. Its main purpose is to ensure the effectiveness (economic, scientific and technical, industrial, social, environmental or other beneficial effect). Therefore, innovative culture of the future manager of the educational institution is an integral, complex, contradictory and dynamic system, being ultimate practical resultoriented, where a certain effect is achieved through interaction of its elements and complex processes.

\section{REFERENCES}

1. Ahmed, P. K. (1998). Culture and climate for innovation European Journal of Innovation Management, 1(1), 30-43 Retrieved from: http://doi.org/10.1108/14601069810199131

2. Amit, R., \& Schoemaker, P. J. H. (1993). Strategic assets and organizational rent. Strategic Management Journal, 14(1), 33-46. Retrieved from: http://doi.org/10.1002/smj.4250140105

3. Creativity Philosophy: Monograph/Improvement. ed. AN Loschilina, NP Frantsuzova. M: Philosophical Society, 2002. 268s.

4. Dobni, C. B. (2008). Measuring innovation culture in organizations. European Journal of Innovation Management, 11(4), 539-559 Retrieved from: http://doi.org/10.1108/14601060810911156

5. Dolgov,V.I. (1999). The acmeological essence of innovative culture of public service personnel. Bulletin of the Chelya binsk University. Avg. 5: Pedagogy. Psychology. 1. 65-71. Retrieved from: http: //www.lib.csu. en/vch/5/1999_01/008.pdf (accessed: 12/15/2014).

6. Drucker, P.F. (2002) Management Challenges for the 21st Century. London: Butter Worth Heinemann.

7. Gendina, N.I. (2008). Information-retrieval thesauruses: main types and fields of application. Scientific and technical libraries. State Public Scientific and Technical Library of Russia. $5-14$.

8. Isaev, V.V. (2000). Roundtable at the Institute of Strategic Innovation. Innovations. 5-6.

9. Kholodkova, L. (2000). Formation of innovative thinking in a system of developing education in a military higher education institution. Dis. Cand. ped. of sciences. St. Petersburg.

10. Kozlova, O.G., Milenkova, R.V. (2007). Innovative culture: essential characteristics: Monograph. Sumy: SSPU named after A.S. Makarenko.

11. Kraśnicka, T., Głód, W., \& Wronka-Pośpiech, M. (2017). Management innovation, pro-innovation organisational culture and enterprise performance: testing the mediation effect. Review of Managerial Science, 1-33. Retrieved from: http://doi.org/10.1007/s11846-017-0229-0

12. Kremen, V.G. (2010). Philosophy of human-centrism in the educational space. Type 2. Kiev: "Knowledge" of Ukraine.

13. Leavy, B. (2005). A leader's guide to creating an innovation culture. Strategy and Leadership, 33(4), 38-45. Retrieved from: http://doi.org/10.1108/10878570510608031

14. Linke, A., \& Zerfass, A. (2011). Internal communication and innovation culture: developing a change framework. Journal of Communication Management, 15(4), 332-348. Retrieved from: http://doi.org/10.1108/13632541111183361

15. Nikolaev, A. (2014). Innovative development and innovative culture. International Journal "Management Theory and Practice”. Retrieved from: http://vasilievaa.narod.ru/ptpu/9_5_01.htm

16. Noskov, V. (2005). Socio-psychological determinants of innovative culture in a liberal arts university. Social psychology. 4 (12). 69-83.

17. Shani, N, Divyapriya, D (2011). Developing Creative and Innovative Culture in Organization, San Blue Enterprises Pvt. Ltd.

18. Smirnov, O.O. (2004). Innovative activity of personnel as a source of growth of competitive advantages of the enterprise. Actual problems of economy. 11 (41). 116-125.

19. Vasilenko, N.D. (2013). Features of innovative culture in neoliberal society. Economics and Law. XXI century. 2.171178 . 